\title{
O QUE ENSINAR: A PERSPECTIVA DISCENTE
}

\author{
Irene C. Rangel BETTI"
}

Inicialmente, responderei a questão deste Seminário dizendo que, em minha opinião, temos sim o que ensinar, mesmo porque, se não acreditasse nisso teria que pedir demissão do meu emprego de professora.

Como o tema proposto possibilita diferentes formas de se observar o fenômeno, preferi observá-lo sob a ótica dos alunos. Assim pensando, decidi investir em uma perspectiva pouco abordada pelos pesquisadores, ou seja, a perspectiva discente.

O que pensam os alunos sobre o que lhes é ensinado?

Objeto de todos os melindres e cuidados possiveis, afinal é por eles, por causa deles e para eles que planejamos, discutimos e propomos diferentes objetivos, conteúdos, estratégias e avaliações, sua opinião nunca é solicitada. Sua participação no planejamento é quase nula, seus interesses são pouco levados em consideração. Até mesmo no 20. grau, quando os alunos não são mais crianças, mas semi-adultos prestes a optar por um modo de vida, ainda continuamos a escolher por eles o conteúdo a ser desenvolvido em aulas de Educação Física.

Algumas pessoas podem argumentar que isto é natural, uma vez que nós, profissionais da área, estudamos para tal. Não posso deixar de discordar, já que experimentei as duas formas de trabalho, ouvindo ou não a opinião dos alunos, e acredito que, quando os alunos puderam opinar, sua participação e aproveitamento foram melhores. É claro que esta forma de atuação exige uma total mudança em nosso modo de pensar e não se presta a todas as faixas etárias; mas acredito que, de alguma forma, mais simples ou mais complexa, os alunos deveriam ter a chance de opinar a respeito do que vai acontecer com eles na aula de Educação Física.

Através então da ótica dos alunos resolvi trazer para este Seminário alguns estudos que se preocuparam com sua opinião. São eles uma pesquisa publicada pela professora Leila T. Machado de Brito, realizada com 150 alunas matriculadas de 5a. a 8a. séries do 10. grau e 1a. a 3a. séries do 20. grau das redes particular e pública de Belo Horizonte, a dissertação de Mestrado do prof. João S. Aguiar, que trouxe a fala de professores e alunos do ensino de 10. grau do Estado de São Paulo e minha dissertação de Mestrado (Betti, 1992), onde foram ouvidos 58 escolares de 10 a 15 anos de ambos os sexos, da rede pública e particular da cidade de Rio Claro.

Por uma análise desses discursos foi possível identificar problemas relacionados à diversificação dos conteúdos, postura do profissional de Educação Física, metodologia de ensino e variáveis interferentes na aprendizagem dos conteúdos.

Em minha dissertação, os alunos reclamaram muito quanto a questão de jogarem sempre a mesma coisa, de não haver mudança no contcúdo.

A professora mudar um pouco, que desde a 5a. série nunca joguei outra coisa, né (handebol) a não ser isso, sempre a mesma coisa. No ano passado veio outra professora (estagiária) que dava exercício, tudo. Acho legal, mas fica muito nisso, poderia fazer outras coisas.

Outros reclamaram de um conteúdo sem muitas opç̃es, apenas basquete ou vôlei, ou seja, não há variedade de conteúdos. Sem chance de opção, os alunos podem até achar que preferem um conteúdo e aí

Departamento de Educação Física, Universidade Estadual Paulista - Rio Claro. 
fica a minha dúvida: preferem por já terem experimentado outro e tiveram chance de escolha, ou por nunca haverem experimentado outro esporte?

- Mais variedade de esportes. Semestre passado era só vôlei, batido! ...Por exemplo: primeiro semestre deveria ser basquete, no segundo handebol, variar mais; foram dois semestres batidos só em vôlei.

O conteúdo apresentado aos alunos de 5a. série do 10 . grau em diante é basicamente o conteúdo esportivo e, mesmo assim apenas algumas modalidades são contempladas. A dança, a ginástica artística, o atletismo, por exemplo, são pouco explorados.

- Eu acho bom fazer Educação Física, mas acho que a professora devia dar outra coisa, ginástica, dança, porque jogar eu não gosto, a não ser vôlei e como vôlei não dá para fazer aqui então eu queria que tivesse outros tipos de jogos, mais tipos e ginástica.

- As lutas, (ou como queiram chamar), como a capoeira, o judô e o karatê nem sequer são citados como conteúdo escolar. A impressão que temos é a de que, mesmo fazendo parte do conteúdo das faculdades estes são reservados aos que podem pagar uma academia, quando para seu aprendizado não há necessidade de um material sofisticado.

Na realidade, as crianças não são preguiçosas, aliás só trocariam as aulas de Educação Física por outra atividade, em outro lugar, se fosse para aprender mais.

- Pra aprender mais eu trocaria. Se fosse um lugar bom e aprendesse mais eu trocaria.

O que chama bastante a atenção nos depoimentos dos alunos é a reclamação básica de que o conteúdo existe, mas o que falta é a vontade do professor em mudar e ensinar.

- Queria que ensinasse a jogar mais, chega aqui e joga, só. Quando tem campeonato a professora ensina. Mas na aula nem aquece. Na maioria das vezes ela fica lá na escola, nem fica na quadra. $O$ capitão é que tira os times. Aí o tempo fica pouco, 10 minutos para cada time, depois tem que mudar, ai fica pouco.

- Gosto, mas é que na 5a. série era bem mais gostoso. A professora não fala mais nada, manda dar volta na quadra e jogar, nos outros anos ela dava mais exercícios. Ah! sei lá, mudar um pouco, chega ai pega a bola e joga, então fica sem graça assim.

- Que a professora incentivasse mais, porque tem muita gente que não joga, treinasse mais, tem muita gente que não sabe mais porque não treina, se a professora desse mais treino, dar mais oportunidade...

Algumas crianças são capazes até de dizer o que fazer para que um grupo não permaneça parado enquanto outro joga (estratégia), ou até mesmo como deveria ser um programa de Educação Física, ou princípios de aprendizagem motora que deveriam ser do conhecimento do professor.

- Ah! eu gosto sabe, mas às vezes enjoa, sempre a mesma coisa, às vezes fica só naquilo enjoa. Muito cansativo... Mudar assim de jogo, por exemplo, em vez de ficar sentado poderia jogar outro jogo, assim ninguém fica vago, uns fazendo esporte e outras jogando no campo queimada, não deixar ninguém vago, entende? Variar um pouco pra não ficar cansativo. Não tem o que eu não gosto, eu gosto de tudo, tem vez que ficar só naquilo, mas não tem parte que eu não gosto.

- Devia treinar um pouco pra depois jogar basquete mesmo. A primeira vez que nós jogamos basquete eu não sabia, e eu ganhei e nunca jogamos, e então elas erravam muito. Então a professora falava muito "Por que erra?" Mas ninguém sabia. Ai devia fazer assim né: primeiro treina a pessoa, pergunta se ela sabia jogar, ai sim, colocava ela pra jogar, né! Por exemplo: primeiro semestre deveria ser basquete, no segundo handebol, variar mais, foram dois semestres batidos só em vôlei. 
A professora Leila M. Brito encontrou os seguintes dados em resposta à questão "O programa de Educação Física deveria conter..."

- mais brincadeiras, mais jogos, dança, esportes $=70 \%$ para 5 a. e $6 a$. séries, $64 \%$ para 7 a. e $8 a$. e $51 \%$ para o 20 . grau.

- conversas, teoria, sugestðes das alunas $=12 \%$ para 5 a. e 6 a. séries, $16 \%$ para 7 a. e $8 a$. e $23 \%$ para o 20. grau. (Brito, 1990).

- competiç̃̃es, campeonatos $=3 \%$ para $5 a$. e 6 a. séries, $8 \%$ para $7 a$. e $8 a$ e $8 \%$ para 20 . grau

A grande diferença de porcentagens apresentadas em favor de mais jogos, brincadeiras, etc, pode sugerir que as alunas necessitavam de uma maior dinâmica nas aulas, maior variedade e oportunidade de movimento. Ao mesmo tempo podemos notar a falta de interesse em competiçðes e campeonatos, o que confirmou dados obtidos em minha pesquisa. onde os alunos demonstram pouco interesse em relação a esses valores.

Analisando as respostas dos alunos podemos verificar claramente o desinteresse crescente pelas aulas de Educação Física. Ainda baseado nos dados da profa. Leila podemos observar que 3\% das alunas de 5a. e 6a. séries acham as atividades desenvolvidas cansativas e repetitivas, proporção que passa a $28 \%$ entre as alunas de 7 a. e 8 a. séries e $40 \%$ no 20 . grau. Se pensarmos que as estratégias e conteúdos utilizados para o desenvolvimento das aulas de Educação Física são basicamente (e infelizmente) os mesmos desde a 5a. série até o 30. ano do 20. grau, não devemos estranhar estes dados.

Todas estas observações deixaram-me extremamente preocupada. Afinal, de que adianta elevar tanto a teoria da Educação Física se, na prática, os professores não estão motivados a aplicá-las? E o que é pior, não percebem ou não lhes interessa perceber, que até seus alunos conseguem enxergar esta prática desmotivada.

Posturas como deixar os alunos esperando do lado de fora, enquanto 12 ou 10 jogam, largar os alunos na quadra e ir tomar café, entregar uma bola e sair, não aparecer nos dias de chuva, chegar atrasado para a primeira aula, sair mais cedo, são comuns e todos percebem. Muito pior quando o discurso é um e a prática outra, como na dissertação do prof. Aguiar:

Professor: "Estou fazendo aquilo, que eu gosto (...) A gente se sente útil sendo professor de Educação Física, porque orienta e colabora com alguma coisa para o beneficio das pessoas e da comunidade".

"Condição ideal para o trabalho não se tem, mas dá para trabalhar. Temos na escola alguns 'medicine-balls' um plinto, dois colchð̃es, três bolas de vôlei, duas de handebal, uma quadra e um campo de futebol perto da escola que também usamos".

"Dou atividades de ginástica para condicionamento fisico, atletismo, futebol de salão e de campo, vôlei e handebol."

Alunos: "A nossa Física é resumida no professor dar uma bola para brincarmos"

"Nas aulas de Educação Física o nosso professor dá uma bola e sai, nós vamos jogar. Às vezes com a bola de vôlei ou basquete jogamos futebol de salão"

"Se não tem material o professor deveria dar outras coisas, como exercícios. Porque não existe só o vôlei, o basquete e futebol na Física, existem várias outras coisas que talvez a gente nem conheça. Não é?

"O nosso professor não tem interesse nem em dar a Educação Física e nem fazer com que a gente aprenda" (Aguiar, 1987, p. 77-82).

Ao contrário, quando o professor trabalha bem, o reconhecimento disto e do conteúdo fica mais esclarecido para os alunos:

- Nesta escola eu aprendi vôlei, dança, atletismo, handebol e exercícios fisicos. Em outra escola que eu estudei, a professora dova uma bola de vôlei em nossa mão e saía, aquilo não era Educação Física, eu nem ia d̀s aulas. A Educação Física depende muito da professora. 
Para finalizar, no meu modo de entender temos o que ensinar, mas em muitos casos não nos damos a esse trabalho. $O$ conteúdo de ginástica. dança, jogos e esportes, com alterações advindas da época em que se vive, vem sendo desenvolvido desde a implantação da Educação Física no Brasil. As habilidades básicas e capacidades perceptivas para a pré-escola e la. a 4a. série do 10. grau são vistas principalmente através do jogo, das brincadeiras populares e das atividades rítmicas, de forma lúdica; no primeiro grau o esporte é o mais desenvolvido, apesar das poucas variações. No 20. e até 30. graus, há um maior grau de confusão, justamente pela forma de aplicação e, conseqüentemente, há um maior número de dispensas. Tudo isto sem contar a questão de valores que, tenho certeza, será abordada na continuidade deste Seminário. O que falta é uma participação efetiva do professor e um maior grau de participação do aluno na escolha dos conteúdos.

Temos que pensar que a escola não é eterna para todos e que, se os alunos não sentirem prazer no que fazem dificilmente continuarão fazendo atividades fisicas após o período escolar. Não podemos restringir a Educação Física somente ao período em que as pessoas passam na escola. Se queremos transformar a Educação Física escolar em Educação Física permanente temos que ter em mente que esta prática deve ser, no mínimo, variada e prazerosa. Acredito que todos deveriam vivenciar o maior número possivel de atividades para que quando saíssem da escola pudessem optar por alguma (ou várias) e praticá-la em suas horas livres, em beneficio de sua qualidade de vida.

Tendo em vista estes depoimentos eu proporia para futuros Seminários, as questões: por que ensinar? como ensinar? e, principalmente, com algumas exceçðes: por que nåo ensinamos?

\section{REFERÊNCIAS BIBLIOGRÁFICAS}

AGUIAR, J.S. Os significados da Educação Física no ensino de 10. grau: depoimentos de professores e alunos. São Paulo, 1987. Dissertação (Mestrado) - Escola de Educação Física. Universidade de São Paulo.

BETГ, I.C.R. O prazer em aulas de Educação Física Escolar: a perspectiva discente. Campinas, 1992. Dissertação (Mestrado) - Universidade Estadual de Campinas.

BRITO, L.T.M. Percepcão da Educação Física escolar em escolas de 10. e 2o. graus em Belo Horizonte M/G (um estudo exploratório). Revista Brasileira de Ciência e Movimento, v.4, n.4, p.7-17, 1990. 